\title{
Analytical validation of a lymphocytic choriomeningitis virus real-time RT-PCR assay
}

\author{
Samuel Cordey ${ }^{\mathrm{a}, \mathrm{b}, \mathrm{c}, *, 1}$, Roland Sahli ${ }^{\mathrm{d}, 1}$, Marie-Laurence Moraz $^{\mathrm{d}}$, Christine Estrade $^{\mathrm{d}}$, \\ Laurence Morandi $^{b, c}$, Pascal Cherpillod ${ }^{\mathrm{a}, b, c}$, Remi N. Charrel ${ }^{\mathrm{e}}$, Stefan Kunz ${ }^{\mathrm{d}}$, Laurent Kaiser ${ }^{\mathrm{a}, \mathrm{b}, \mathrm{c}}$ \\ a Swiss National Reference Centre for Emerging Viral Diseases, University of Geneva Hospitals, Geneva, Switzerland \\ ${ }^{\mathrm{b}}$ Laboratory of Virology, University of Geneva Hospitals, Geneva, Switzerland \\ ${ }^{c}$ University of Geneva Medical School, Geneva, Switzerland \\ ${ }^{\mathrm{d}}$ Institute of Microbiology of the Centre Hospitalier Universitaire Vaudois and University of Lausanne, Lausanne, Switzerland \\ e Unité des Virus Emergents (UMR190), Université de la Méditerranée - Institut de Recherche pour le Développement, Marseille, France
}

Article history:

Received 9 March 2011

Received in revised form 24 May 2011

Accepted 21 June 2011

Available online 6 July 2011

\section{Keywords:}

Lymphocytic choriomeningitis virus

Real-time RT-PCR

Cerebrospinal fluid

Prevalence

\begin{abstract}
A B S T R A C T
Lymphocytic choriomeningitis virus (LCMV) is a rare cause of central nervous system disease in humans Screening by real-time RT-PCR assay is of interest in the case of aseptic meningitis of unknown etiology. A specific LCMV real-time RT-PCR assay, based on the detection of genomic sequences of the viral nucleoprotein (NP), was developed to assess the presence of LCMV in cerebrospinal fluids (CSF) sent for viral screening to a Swiss university hospital laboratory.

A 10-fold dilution series assay using a plasmid containing the cDNA of the viral NP of the LCMV isolate Armstrong (Arm) 53b demonstrated the high sensitivity of the assay with a lowest detection limit of $\leq 50$ copies per reaction. High sensitivity was confirmed by dilution series assays in a pool of human CSF using four different LCMV isolates (Arm53b, WE54, Traub and E350) with observed detection limits of $\leq 10 \mathrm{PFU} / \mathrm{ml}$ (Arm53b and WE54) and $1 \mathrm{PFU} / \mathrm{ml}$ (Traub and E350).

Analysis of $130 \mathrm{CSF}$ showed no cases of acute infection. The absence of positive cases was confirmed by a published PCR assay detecting all Old World arenaviruses.

This study validates a specific and sensitive real-time RT-PCR assay for the diagnosis of LCMV infections. Results showed that LCMV infections are extremely rare in hospitalized patients western in Switzerland.
\end{abstract}

(C) 2011 Elsevier B.V. All rights reserved.

Lymphocytic choriomeningitis virus (LCMV), the prototypic member of the Arenaviridae family, was isolated from a fatal case of aseptic meningitis during the St. Louis encephalitis epidemic in 1933 (Armstrong and Lillie, 1934).

In nature, LCMV is maintained by congenital transmission within infected populations of the mouse species Mus domesticus and Mus musculus. LCMV infects readily other rodents, including hamsters and guinea pigs. The LCMV carrier state is characterized by persistent infection with high virus loads in serum and several organs in the absence of a virus-specific immune response and overt pathology. Humans are accidental hosts and the main route of transmission is by contact with infected rodents that shed large

\footnotetext{
* Corresponding author at: Laboratory of Virology, Division of Infectious Diseases, University of Geneva Hospitals, 4 Rue Gabrielle-Perret-Gentil, 1211 Geneva 14, Switzerland. Tel.: +4122 3724079; fax: +41223724097.

E-mail address: samuel.cordey@hcuge.ch (S. Cordey).

1 These authors contributed equally to this work.
}

quantities of virus in nasal secretions, saliva, milk, semen, urine, and feces.

Although human LCMV cases are observed throughout the year, disease incidence increases in winter, due probably to the movement of infected rodents indoors, thus increasing the risk of human exposure (Barton et al., 1993). In immunocompetent adult individuals, LCMV infection is either asymptomatic or results in a self-limiting febrile illness associated rarely with fatalities. Signs and symptoms are largely non-specific, including fever, myalgia, and malaise. Central nervous system involvement manifests as headache and photophobia, associated with nausea or vomiting. In most cases, infected individuals recover completely, but this may require several months. Severe aseptic meningitis or meningoencephalitis is observed only in a minority of cases (Barton et al., 1993). Human-to-human transmission has been documented through organ donation associated with severe disease in the immunocompromised recipient (Fischer et al., 2006), and congenital infections leading to severe and irreversible brain (Barton et al., 1993; Barton and Mets, 2001; Bonthius et al., 2007; Wright et al., 
1997) and retinal (Bonthius et al., 2007; Mets et al., 2000) injury have been described.

Acute human LCMV infections are diagnosed generally by virus isolation from CSF and the use of serological testing or classical PCR assays (Park et al., 1997; Emonet et al., 2007) offer the possibility to detect pre- and postnatal LCMV infections. More recently, SYBR Green-based quantitative PCR assays were developed to quantify LCMV in infected mice (McCausland and Crotty, 2008; Emonet et al., 2007). Due to their higher sensitivity and specificity compared to both viral culture and immunofluorescence-based detection methods, RT-PCR viral assays are favored for the diagnosis of viral infection in most routine laboratories.

A real-time RT-PCR assay with specific primers and probes adapted to published LCMV sequences available was developed to screen acute LCMV infections in CSF. The use of a specific probe has the main advantage to increase the LCMV-specificity compared to SYBR Green PCR methods. Over a period of two years, all hospitalized pediatric cases and adults less than 25-years-old for whom a screening for viral meningoencephalitis was required by the physician at the University of Geneva Hospitals were screened for LCMV infections using this real-time RT-PCR.

To identify primers and probes, conserved regions specific to LCMV were screened based on an extensive alignment of all LCMV and Old World arenavirus's sequences available in Genbank in August 2010, including all recently discovered arenaviruses (Briese et al., 2009; Gunther et al., 2009; Palacios et al., 2008). This alignment allowed to pinpoint a conserved region within the viral nucleoprotein (NP) gene. Primer pairs were designed to correspond to the least number of combinations matching perfectly each distinct LCMV sequence. Therefore, the primers used in the PCR are constituted of a mix of 9 and 8 selected forward and reverse primers, respectively (Fig. 1). Primers and probe (Eurogentech, Seraing, Belgium) were screened by NCBI nucleotide BLAST (Altschul et al., 1990) to exclude any cross-reactions with human cellular sequences and distantly related viruses. The probe was labelled at the $5^{\prime}$ end with the 6-carboxyfluorescein (FAM) and at the $3^{\prime}$ end with the BHQ1 black hole quencher. In brief, the viral genome was extracted individually from $400 \mu$ l of samples using the NucliSENS easyMAG (bioMérieux, Geneva, Switzerland) nucleic acid kit, according to the manufacturer's instructions. In addition, $20 \mu \mathrm{l}$ of standardized canine distemper virus (CDV) of known concentration was added to each sample before extraction to control for intra- and inter-assay variability as previously described (Cordey et al., 2010). To remove a maximum of DNA contaminant in eluates, a DNAse treatment was done using the DNA-free kit (Ambion, Rotkreuz, Switzerland), according to the manufacturer's instructions. This step was necessary for optimal sensitivity in the presence of more than $5 \mathrm{ng} / \mathrm{ml}$ of human DNA in the sample. The synthesis of cDNA was performed with random hexamers (Roche, Rotkreuz, Switzerland) at $42{ }^{\circ} \mathrm{C}$ using the Superscript II Reverse Transcriptase (Invitrogen, Basel, Switzerland), according to the manufacturer's instructions. cDNA was amplified using a TaqMan $^{\circledR} 7500$ (Applied Biosystems, Rotkreuz, Switzerland) thermocycler under the following cycling conditions: $95^{\circ} \mathrm{C}$ for $9 \mathrm{~min} ; 50$ cycles of $15 \mathrm{~s}$ at $95^{\circ} \mathrm{C}$ and $1 \mathrm{~min}$ at $58^{\circ} \mathrm{C}$. After assessment of optimal primers/probe concentrations, the reaction was performed in $20 \mu \mathrm{l}$ containing $1 \times$ TaqMan ${ }^{\circledR}$ Universal PCR Master Mix (Applied Biosystems), $0.2 \mu \mathrm{M}$ of each individual LCMV forward primer, $0.2 \mu \mathrm{M}$ of each individual LCMV reverse primer, $0.2 \mu \mathrm{M}$ of LCMV probe per reaction, and $5 \mu \mathrm{l}$ of cDNA. Results were analyzed using the SDS 1.4 program (Applied Biosystems).

The analytical sensitivity of the LCMV real-time RT-PCR was determined using the mammalian expression plasmid pcAGGS containing the cDNA of the NP derived from the LCMV isolate Armstrong (Arm) 53b in 10-fold serial dilutions. The experiment showed a linear range between 50 and $5 \times 10^{4}$ copies of input with the lowest limit of detection being $\leq 50$ copies per reaction (Fig. 2). Of note, 5 plasmid copies were detected only in one of the triplicate wells. Sensitivity was assessed further using crude stocks of the LCMV isolates LCMV-Arm53b, LCMV-WE54, LCMV-Traub, and LCMV-E350 grown in BHK21 cells (Table 1) which were diluted serially in a pool of human CSF negative for LCMV. The four LCMV isolates showed low limits of detection in plaque-forming units (PFU) determined by immunofocus assay ( $\leq 10 \mathrm{PFU} / \mathrm{ml}$ for Arm53b, $\leq 10 \mathrm{PFU} / \mathrm{ml}$ for WE54, $\leq 1 \mathrm{PFU} / \mathrm{ml}$ for Traub, and $\leq 1 \mathrm{PFU} / \mathrm{ml}$ for E350). Similarly, dilution series assays performed in phosphate buffered saline showed a reproducible detection limit of $\leq 1 \mathrm{PFU} / \mathrm{ml}$ for each LCMV isolate, thus suggesting the presence of defective interfering particles, a well-known phenomenon with LCMV (Martinez Peralta and Lehmann-Grube, 1983; Francis and Southern, 1988; Meyer and Southern, 1997). In addition, the recently identified LCMV-Marseille strain supernatant (Emonet et al., 2007) has also been tested positive. To assess the potential specificity of this real-time RT-PCR, the genetically more distant New World arenaviruses, Junin virus and Pichinde virus isolates, as well as individual pcAGGS plasmids containing the cDNA of the NP derived from Lassa virus, Machupo virus, Tacaribe virus, Latino virus, and Whitewater Arroyo virus were examined also (Table 1). Consistent with their phylogenetic distance from LCMV, none of these arenaviruses was detected by the assay, except Lassa virus for which a weak cross-reaction was observed at a very high concentration, although a minimum of 1 and 4 mismatches are present in the forward and the reverse primer sets, respectively. This cross-reaction can be explained by the extremely high sequence homology between Lassa and LCMV. Therefore, cross-reaction events should be considered for samples with $C_{\mathrm{T}}$ (threshold value) values close to the limit of positivity determined at $40 C_{\mathrm{T}}$. Finally, a large panel of unrelated virus isolates, including herpes simplex virus, varicella zoster virus, Epstein-Barr virus, JC virus, measles virus, enterovirus and parechovirus, belonging to other virus families known to lead potentially to meningitis or meningoencephalitis complications, remained undetected with the LCMV real-time RT-PCR.

All hospitalized pediatric cases and adults less than 25 years old who underwent a CSF screening with negative results for selected viral infections (enterovirus, parechovirus, herpes simplex virus, varicella zoster virus, Epstein-Barr virus, JC virus, and/or measles virus) between October 2008 and September 2010 were assessed for LCMV with the newly developed real-time RT-PCR assay.

Of a total of 130 CSF samples (56 female [43\%]; 74 male [57\%]; median age, 2 years old), 51 (39\%) were collected in infants less than 1-year-old. The clinical syndromes ranged from meningitis, encephalitis, convulsions, and other central nervous system diseases. The analysis covers two winter seasons known to represent the peak window period of infection.

None of the 130 CSF samples was found positive for LCMV. Since the design of the specific LCMV primers and probe was based on the available sequence information in Genbank at that time, the presence of yet unknown strains of LCMV circulating in rodents and transmitted to humans cannot be ruled out. To address this issue, a previously published pan-arenavirus RT-PCR (Vieth et al., 2007) capable of detecting all currently known Old World arenavirus species, including LCMV, Lassa virus, and Mobala virus, was used. When applied to the 130 CSF samples, none was positive for LCMV, similar to the results obtained with the specific LCMV real-time RT-PCR assay described above.

This report describes the analytical validation of a LCMV realtime RT-PCR assay allowing rapid detection of LCMV strains that have been shown to infect humans.

Despite important efforts to contact most investigators with documented cases of human LCMV infections over the last few years, it was not possible to obtain such rare clinical samples due 

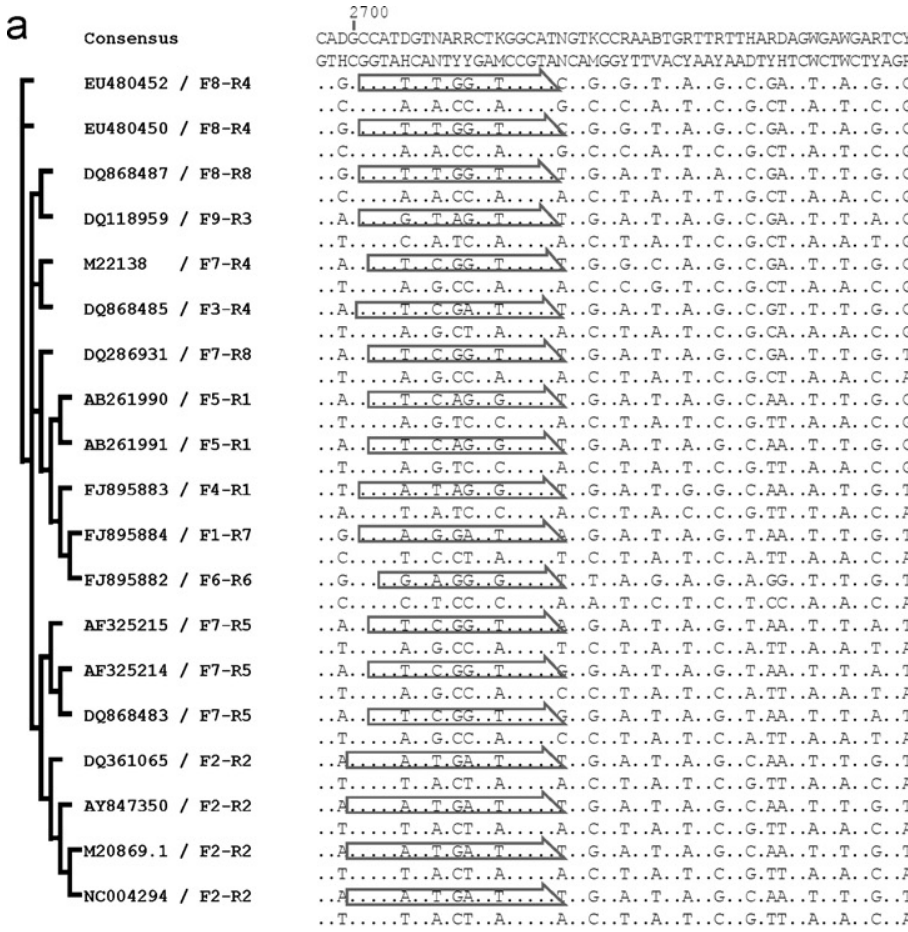

2755

tCaCatCCavacyct BACNACNCCRBTNKYNCYYYGYTGRGGBYKY CTCATY CCWACYATBTGYARDRTYT A GTGTAGGGTBT GRGAVTGNTGNGGYVANMRNGRRRCRACYCCVRMRGAGTARGGNTGRTAVA.CRTYHYARAC

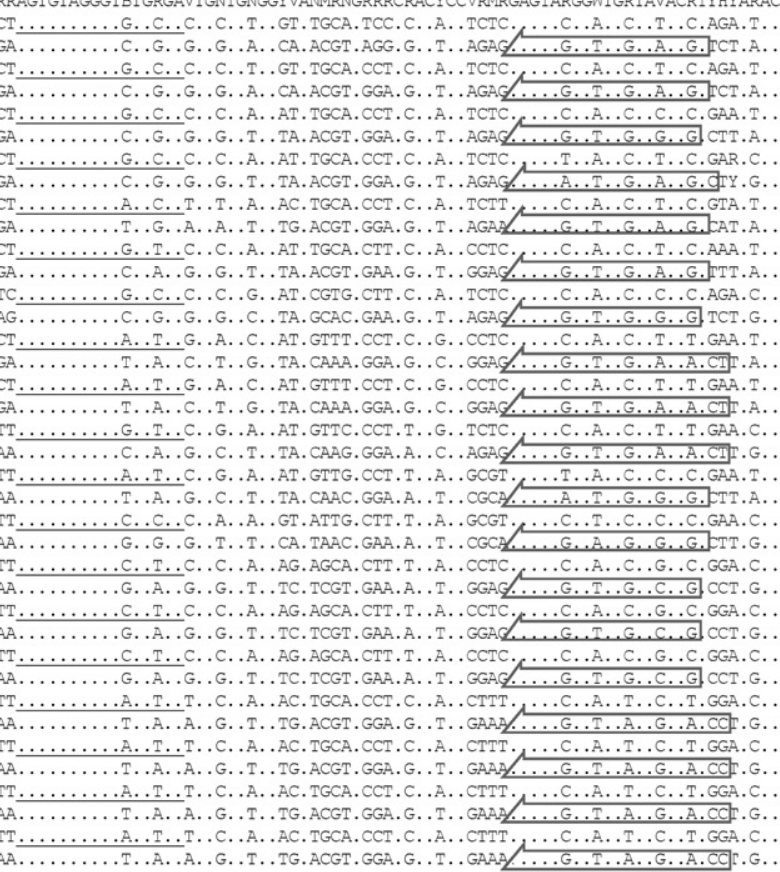

b

Sequence $\left(5^{\prime}-3^{\prime}\right)$

Concentration $[\mathrm{nM}]$ in reaction

$\begin{array}{ll}\text { LCMV_NP-For1 } & \text { CCATAGTGAGACTTGGCAT } \\ \text { LCMV_NP-For2 } & \text { GCCATAGTTAGACTTGGCAT } \\ \text { LCMV_NP-For3 } & \text { CCATTGTCAGACTTGGCAT } \\ \text { LCMV_NP-For4 } & \text { CCATAGTTAAGCTGGGCAT } \\ \text { LCMV_NP-For5 } & \text { CATTGTCAAGCTGGGCAT } \\ \text { LCMV_NP-For6 } & \text { ATGGTAAGGCTGGGCAT } \\ \text { LCMV_NP-For7 } & \text { CATTGTCAGGCTTGGCAT } \\ \text { LCMV_NP-For8 } & \text { CCATTGTTAGGCTTGGCAT } \\ \text { LCMV_NP-For9 } & \text { CCATGGTTAAGCTTGGCAT } \\ & \\ \text { LCMV_NP-Rev1 } & \text { TCTACAAATGGTTGGGATGAG } \\ \text { LCMV_NP-Rev2 } & \text { CCTACAGATAGTTGGGATGAG } \\ \text { LCMV_NP-Rev3 } & \text { CTGCAAATGGTTGGAATGAG } \\ \text { LCMV_NP-Rev4 } & \text { TGCAAATGGTTGGGATGAG } \\ \text { LCMV_NP-Rev5 } & \text { GCACATGGTTGGGATGAG } \\ \text { LCMV_NP-Rev6 } & \text { TGCAGATGGTAGGGATGAG } \\ \text { LCMV_NP-Rev7 } & \text { TGCAGATGGTTGGAATGAG } \\ \text { LCMV_NP-Rev8 } & \text { GCAGATGGTTGGGATGAG }\end{array}$

200

200

200

200

200

200

200

200

200

200

200

200

200

200

200

200

200

LCMV_NP-Probe FAM- tCaCatCCcavacyct-TAMRA upper case $=$ LNA

200

Fig. 1. Primers and probe for LCMV real-time RT-PCR assay. (a) Nineteen LCMV NP reference sequences indicated by their Genbank accession numbers (EU480452, EU480450, DQ868487, DQ118959, M22138, DQ868485, DQ286931, AB261990, AB261991, FJ895883, FJ895884, FJ895882, AF325215, AF325214, DQ868483, DQ361065, AY847350, M20869.1 and NC004294) were aligned with the MAFFT algorithm in the Geneious software package. Consensus was established with $100 \%$ identical residue at each position. Conserved residues are indicated by dots and polymorphic residues by their actual IUPAC code. The most conserved area, shown here as double stranded cDNA, was used as the target for the real-time RT-PCR assay. The primer sequences are boxed in strand-specific arrows. The forward primers (F1-F9) are on the coding (upper) strand and the reverse primers (R1-R8) are on the complementary (lower) strand. The probe is shown in bold fonts in the upper strand of the consensus sequence; capital letters indicate LNA residues used to increase its melting temperature. LNA residues were positioned within this highly conserved area to limit the risk of false negativity with unknown LCMV sequences. Numbers on top refer to the $5^{\prime}$ end of the primer/probe positions within the NP open reading frame using the Armstrong strains as reference. LCMV phylogeny is depicted by the tree on the left-hand side pointing to each individual reference sequence. Primer combination adapted to the amplification of each genotype is shown to the right of the accession number and refers to the primer names indicated in (b) (F, For; R, Rev).

to the very limited amount of CSF collected initially. Nevertheless, serial dilutions of both Arm-derived plasmid and different LCMV strains cultures in a pool of CSF confirmed the high analytical sensitivity of the new assay with limits of detection reaching $\leq 50$ copies per reaction and $\leq 10$ or $1 \mathrm{PFU} / \mathrm{ml}$, respectively, indicating a potential high clinical sensitivity.

Irrespective of the PCR assay used (LCMV specific real-time RT-PCR and classical broad range arenavirus PCR), LCMV was not detected in any CSF samples over the study period. These results show the extremely low incidence of LCMV infections leading to hospital admission for acute meningoencephalitis in western Switzerland and confirm previous prospective surveillance investigations conducted elsewhere. For instance, Park et al. (1997) found no positive case for LCMV among a total of 813 CSF samples collected over a one-year period at two Birmingham (UK) hospitals. Only extensive serological studies at country level may reveal the prevalence of LCMV within the human population. 
Table 1

Performance of the LCMV real-time RT-PCR for the detection of different LCMV and other arenavirus strains.

\begin{tabular}{|c|c|c|c|c|}
\hline Strain & L CMV real-time RT-PCR & Limit of detection & Slope & $R^{2}$ \\
\hline LCMV-ARM53b & Positive & $\leq 10 \mathrm{PFU} / \mathrm{ml}$ (in CSF) & 3.62 & 1 \\
\hline LCMV-WE54 & Positive & $\leq 10 \mathrm{PFU} / \mathrm{ml}$ (in CSF) & 3.91 & 0.99 \\
\hline LCMV-Traub & Positive & $\leq 1 \mathrm{PFU} / \mathrm{ml}($ in $\mathrm{CSF})$ & 3.87 & 1 \\
\hline LCMV-E350 & Positive & $\leq 1 \mathrm{PFU} / \mathrm{ml}($ in CSF $)$ & 3.65 & 1 \\
\hline LCMV-Marseille & Positive & $\overline{N D}$ & ND & ND \\
\hline Lassa & Weak positive cross-reaction $\left(C_{\mathrm{T}}>39\right)$ & Tested for $10^{4}$ plasmid copies/PCR & & \\
\hline Tacaribe & Negative & Tested for $10^{4}$ plasmid copies/PCR & & \\
\hline Machupo & Negative & Tested for $10^{4}$ plasmid copies/PCR & & \\
\hline Latino & Negative & Tested for $10^{4}$ plasmid copies/PCR & & \\
\hline Whitewater Arroyo & Negative & Tested for $10^{4}$ plasmid copies/PCR & & \\
\hline Junin & Negative & Tested for $10^{5}$ copies $/ \mathrm{ml}$ (in plasma) & & \\
\hline Pichinde & Negative & Tested for $10^{5}$ copies/ml (in plasma) & & \\
\hline
\end{tabular}

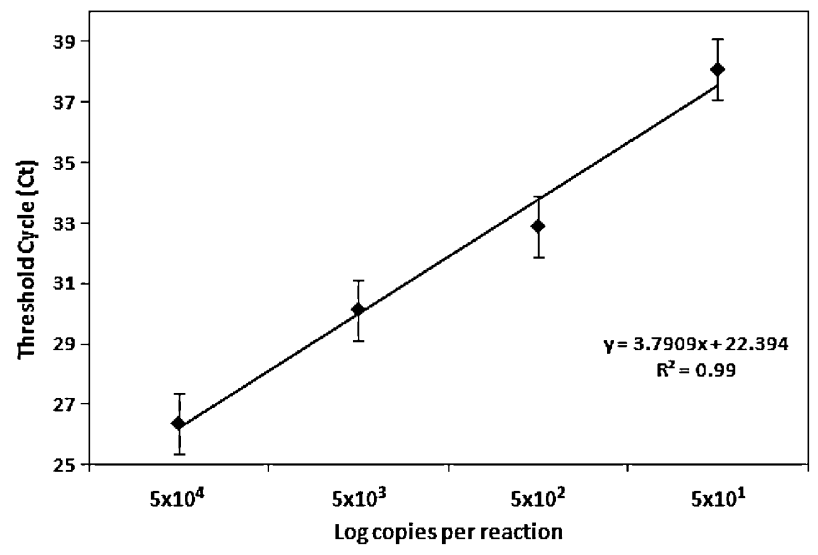

Fig. 2. Analytical sensitivity of the LCMV real-time RT-PCR assay. 10-Fold serial dilutions of Armstrong-derived plasmid ( $5 \times 10^{4}-5 \times 10^{1}$ copies per reaction) were tested by real-time RT-PCR assay. The log of copy numbers is plotted versus the threshold cycle $\left(C_{\mathrm{T}}\right)$. Each dot represents the average of three independent experiments. Of note, a dilution with $5 \times 10^{0}$ plasmid copies showed positive detection in only one single triplicate. It was not considered for slope calculation. Errors bars indicate standard deviations.

The real-time RT-PCR assay described here provides a sensitive and adapted tool for specialized clinical laboratories.

Although the current study did not reveal the presence of acute LCMV infection in children and young adults over the past two years in western Switzerland, potential infections should not be overlooked as clinical complications related to LCMV have been observed in sporadic cases throughout the world (Asnis et al., 2010; Ceianu et al., 2008; Emonet et al., 2007; Sosa et al., 2009). In addition, this real-time RT-PCR assay could be used in rodents, particularly in pet shops, as they represent the principal LCMV reservoir.

\section{Competing interests}

None declared.

\section{Ethical approval}

Not required.

\section{Acknowledgements}

We would like to thank Prof. Stephan Günther from the Bernhard Nocht Institute, Hamburg, Germany, for providing us with the Old World Pan-arenavirus updated PCR assay. We are also grateful to Rosemary Sudan for editorial assistance. This study was supported by the Swiss Federal Office of Public Health (L.K.) and by funds from the University of Lausanne (S.K.).

\section{References}

Altschul, S.F., Gish, W., Miller, W., Myers, E.W., Lipman, D.J., 1990. Basic local alignment search tool. J. Mol. Biol. 215, 403-410.

Armstrong, C., Lillie, R.D., 1934. Experimental LCM of monkeys and mice produced by a virus encountered in studies of the 1933 Saint Louis encephalitis epidemic. Public Health Rep. 49, 1019-1027.

Asnis, D.S., Muana, O., Kim, D.G., Garcia, M., Rollin, P.E., Slavinski, S., 2010. Lymphocytic choriomeningitis virus meningitis, New York, NY USA, 2009. Emerg. Infect. Dis. 16, 328-330.

Barton, L.L., Budd, S.C., Morfitt, W.S., Peters, C.J., Ksiazek, T.G., Schindler, R.F., Yoshino, M.T., 1993. Congenital lymphocytic choriomeningitis virus infection in twins. Pediatr. Infect. Dis. J. 12, 942-946.

Barton, L.L., Mets, M.B., 2001. Congenital lymphocytic choriomeningitis virus infection: decade of rediscovery. Clin. Infect. Dis. 33, 370-374.

Bonthius, D.J., Wright, R., Tseng, B., Barton, L., Marco, E., Karacay, B., Larsen, P.D., 2007. Congenital lymphocytic choriomeningitis virus infection: spectrum of disease. Ann. Neurol. 62, 347-355.

Briese, T., Paweska, J.T., McMullan, L.K., Hutchison, S.K., Street, C., Palacios, G., Khristova, M.L., Weyer, J., Swanepoel, R., Egholm, M., Nichol, S.T., Lipkin, W.I., 2009. Genetic detection and characterization of Lujo virus, a new hemorrhagic feverassociated arenavirus from southern Africa. PLoS Pathog. 5, e1000455.

Ceianu, C., Tatulescu, D., Muntean, M., Molnar, G.B., Emmerich, P., Gunther, S. Schmidt-Chanasit, J., 2008. Lymphocytic choriomeningitis in a pet store worker in Romania. Clin. Vaccine Immunol. 15, 1749.

Cordey, S., Junier, T., Gerlach, D., Gobbini, F., Farinelli, L., Zdobnov, E.M., Winther, B. Tapparel, C., Kaiser, L., 2010. Rhinovirus genome evolution during experimental human infection. PLoS One 5, e10588.

Emonet, S., Retornaz, K., Gonzalez, J.P., de Lamballerie, X., Charrel, R.N., 2007. Mouseto-human transmission of variant lymphocytic choriomeningitis virus. Emerg. Infect. Dis. 13, 472-475.

Fischer, S.A., Graham, M.B., Kuehnert, M.J., Kotton, C.N., Srinivasan, A., Marty, F.M., Comer, J.A., Guarner, J., Paddock, C.D., DeMeo, D.L., Shieh, W.J., Erickson, B.R., Bandy, U., DeMaria Jr., A., Davis, J.P., Delmonico, F.L., Pavlin, B., Likos, A., Vincent, M.J., Sealy, T.K., Goldsmith, C.S., Jernigan, D.B., Rollin, P.E., Packard, M.M., Patel, M., Rowland, C., Helfand, R.F., Nichol, S.T., Fishman, J.A., Ksiazek, T., Zaki, S.R., 2006. Transmission of lymphocytic choriomeningitis virus by organ transplantation. N. Engl. J. Med. 354, 2235-2249.

Francis, S.P., Southern, P.J., 1988. Molecular analysis of viral RNAs in mice persistently infected with lymphocytic choriomeningitis virus. J. Virol. 62, 1251-1257.

Gunther, S., Hoofd, G., Charrel, R., Roser, C., Becker-Ziaja, B., Lloyd, G., Sabuni, C., Verhagen, R., van der Groen, G., Kennis, J., Katakweba, A., Machang'u, R., Makundi, R., Leirs, H., 2009. Mopeia virus-related arenavirus in natal multimammate mice, Morogoro, Tanzania. Emerg. Infect. Dis. 15, 2008-2012.

Martinez Peralta, L., Lehmann-Grube, F., 1983. Properties of lymphocytic choriomeningitis virus interfering particles. Arch. Virol. 77, 61-69.

McCausland, M.M., Crotty, S., 2008. Quantitative PCR technique for detecting lymphocytic choriomeningitis virus in vivo. J. Virol. Methods 147, 167-176.

Mets, M.B., Barton, L.L., Khan, A.S., Ksiazek, T.G., 2000. Lymphocytic choriomeningitis virus: an underdiagnosed cause of congenital chorioretinitis. Am. J. Ophthalmol. 130, 209-215.

Meyer, B.J., Southern, P.J., 1997. A novel type of defective viral genome suggests a unique strategy to establish and maintain persistent lymphocytic choriomeningitis virus infections. J. Virol. 71, 6757-6764.

Palacios, G., Druce, J., Du, L., Tran, T., Birch, C., Briese, T., Conlan, S., Quan, P.L., Hui, J., Marshall, J., Simons, J.F., Egholm, M., Paddock, C.D., Shieh, W.J., Goldsmith, C.S., Zaki, S.R., Catton, M., Lipkin, W.I., 2008. A new arenavirus in a cluster of fatal transplant-associated diseases. N. Engl. J. Med. 358, 991-998. 
Park, J.Y., Peters, C.J., Rollin, P.E., Ksiazek, T.G., Gray, B., Waites, K.B., Stephensen, C.B., 1997. Development of a reverse transcription-polymerase chain reaction assay for diagnosis of lymphocytic choriomeningitis virus infection and its use in a prospective surveillance study. J. Med. Virol. 51, 107-114.

Sosa, L.E., Gupta, S., Juthani-Mehta, M., Hadler, J.L., 2009. Meningitis in a college student in Connecticut, 2007. J. Am. Coll. Health 58, $12-14$.
Vieth, S., Drosten, C., Lenz, O., Vincent, M., Omilabu, S., Hass, M., Becker-Ziaja, B., te Meulen, J., Nichol, S.T., Schmitz, H., Gunther, S., 2007. RT-PCR assay for detection of Lassa virus and related Old World arenaviruses targeting the L gene. Trans. R. Soc. Trop. Med. Hyg. 101, 1253-1264.

Wright, R., Johnson, D., Neumann, M., Ksiazek, T.G., Rollin, P., Keech, R.V., Bonthius, D.J., Hitchon, P., Grose, C.F., Bell, W.E., Bale Jr., J.F., 1997. Congenital lymphocytic choriomeningitis virus syndrome: a disease that mimics congenital toxoplasmosis or Cytomegalovirus infection. Pediatrics 100, E9. 